\title{
Adaptive bacterial foraging oriented particle swarm optimization algorithm for solving optimal reactive power dispatch problem
}

\author{
K. Lenin ${ }^{1, ~ *, ~ B . ~ R a v i n d r a n a t h ~}$ Reddy $^{2}$, M. Surya Kalavathi ${ }^{3}$ \\ ${ }^{1}$ Research Scholar, Jawaharlal Nehru Technological University Kukatpally, Hyderabad 500 085, India \\ ${ }^{2}$ Deputy Executive Engineer, Jawaharlal Nehru Technological University Kukatpally, Hyderabad 500 085, India \\ ${ }^{3}$ Professor of Electrical and Electronics Engineering, Jawaharlal Nehru Technological University Kukatpally, Hyderabad 500 085, India
}

\section{Email address:}

gklenin@gmail.com (K. Lenin)

\section{To cite this article:}

K. Lenin, B. Ravindranath Reddy, M. Surya Kalavathi. Adaptive Bacterial Foraging Oriented Particle Swarm Optimization Algorithm for Solving Optimal Reactive Power Dispatch Problem. International Journal of Energy and Power Engineering.

Vol. 3, No. 1, 2014, pp. 1-6. doi: 10.11648/j.ijepe.20140301.11

\begin{abstract}
This paper presents an algorithm for solving the multi-objective reactive power dispatch problem in a power system. Modal analysis of the system is used for static voltage stability assessment. Loss minimization and maximization of voltage stability margin are taken as the objectives. Generator terminal voltages, reactive power generation of the capacitor banks and tap changing transformer setting are taken as the optimization variables. Evolutionary algorithm and Swarm Intelligence algorithm (EA, SI), a part of Bio inspired optimization algorithm, have been widely used to solve numerous optimization problem in various science and engineering domains. Bacterial Foraging Optimization Algorithm (BFOA) has recently emerged as a very powerful technique for real parameter optimization. In order to overcome the delay in optimization and to further enhance the performance of $\mathrm{BFO}$, this paper proposed a new hybrid algorithm combining the features of BFOA and Particle Swarm Optimization (PSO) called Adaptive bacterial foraging oriented particle swarm optimization (ABF-PSO) for solving reactive power dispatch problem .The simulation results demonstrate good performance of the ABF-PSO in solving an optimal reactive power dispatch problem. In order to evaluate the proposed algorithm, it has been tested on IEEE 30 bus system and compared to other algorithms reported those before in literature. Results show that (ABF-PSO) is more efficient than others for solution of single-objective ORPD problem.
\end{abstract}

Keywords: Bacterial Foraging Optimization Algorithm, Particle Swarm Optimization, Optimal Reactive Power, Transmission Loss

\section{Introduction}

Optimal reactive power dispatch problem is one of the difficult optimization problems in power systems. The sources of the reactive power are the generators, synchronous condensers, capacitors, static compensators and tap changing transformers. The problem that has to be solved in a reactive power optimization is to determine the required reactive generation at various locations so as to optimize the objective function. Here the reactive power dispatch problem involves best utilization of the existing generator bus voltage magnitudes, transformer tap setting and the output of reactive power sources so as to minimize the loss and to enhance the voltage stability of the system. It involves a non linear optimization problem. Various mathematical techniques have been adopted to solve this optimal reactive power dispatch problem. These include the gradient method [1, 2], Newton method [3] and linear programming [4-7].The gradient and Newton methods suffer from the difficulty in handling inequality constraints. To apply linear programming, the input- output function is to be expressed as a set of linear functions which may lead to loss of accuracy. Recently

Global Optimization techniques such as genetic algorithms have been proposed to solve the reactive power flow problem [8.9]. In recent years, the problem of voltage stability and voltage collapse has become a major concern in power system planning and operation. To enhance the voltage stability, voltage magnitudes alone will not be a reliable indicator of how far an operating point is from the 
collapse point [10]. The reactive power support and voltage problems are intrinsically related. Hence, this paper formulates the reactive power dispatch as a multi-objective optimization problem with loss minimization and maximization of static voltage stability margin (SVSM) as the objectives. Voltage stability evaluation using modal analysis [10] is used as the indicator of voltage stability. Natural selection tends to eliminate animals with poor foraging strategies and favor the propagation of genes of those animals that have successful foraging strategies since they are more likely to enjoy reproductive success. After many generations poor foraging strategies are either eliminated or shaped into good ones. Based on the researches on the foraging behavior of E-coli bacteria K.M. Passino proposed a new Evolutionary computation technique known as Bacterial Foraging Optimization Algorithm (BFOA) [11], briefly explained in the following sections. However, during the process of chemo taxis, the BFOA depends on random search directions which may lead to delay in reaching global solution. In order to speed the convergence of Bacterial Foraging Optimization W. Karoni had proposed an improved BFOA namely BF-PSO [12]. The BF-PSO algorithm borrowed the ideas of velocity updating from particle swarm optimization (PSO), the search directions specified by the tumble of bacteria are oriented by the individual best location and global best locations concurrently. To reduce the time of optimization and to accelerate the convergence speed of group of bacteria near global optima for this BFO-PSO we propose a new hybrid algorithm "ABF-PSO" in which the chemo tactic step had been made adaptive. The performance of (ABF-PSO) has been evaluated in standard IEEE 30 bus test system and the results analysis shows that our proposed approach outperforms all approaches investigated in this paper. The performance of (ABF-PSO) has been evaluated in standard IEEE 30 bus test system and the results analysis shows that our proposed approach outperforms all approaches investigated in this paper.

\section{Voltage Stability Evaluation}

\subsection{Modal Analysis for Voltage Stability Evaluation}

Modal analysis is one of the methods for voltage stability enhancement in power systems. In this method, voltage stability analysis is done by computing Eigen values and right and left Eigen vectors of a jacobian matrix. It identifies the critical areas of voltage stability and provides information about the best actions to be taken for the improvement of system stability enhancements. The linearized steady state system power flow equations are given by.

$$
\left[\begin{array}{l}
\Delta \mathrm{P} \\
\Delta \mathrm{Q}
\end{array}\right]=\left[\begin{array}{cc}
\mathrm{J}_{\mathrm{p} \theta} & \mathrm{J}_{\mathrm{pv}} \\
\mathrm{J}_{\mathrm{q} \theta} & \mathrm{J}_{\mathrm{QV}}
\end{array}\right]
$$

Where

$\Delta \mathrm{P}=$ Incremental change in bus real power.
$\Delta \mathrm{Q}=$ Incremental change in bus reactive Power injection

$\Delta \theta=$ incremental change in bus voltage angle.

$\Delta \mathrm{V}=$ Incremental change in bus voltage Magnitude

$\mathrm{J}_{\mathrm{p} \theta}, \mathrm{J}_{\mathrm{PV}}, \mathrm{J}_{\mathrm{Q} \theta}, \mathrm{J}_{\mathrm{QV}}$ jacobian matrix are the sub-matrixes of the System voltage stability is affected by both $\mathrm{P}$ and Q. However at each operating point we keep P constant and evaluate voltage stability by considering incremental relationship between $\mathrm{Q}$ and $\mathrm{V}$.

To reduce (1), let $\Delta \mathrm{P}=0$, then.

$$
\begin{gathered}
\Delta \mathrm{Q}=\left[\mathrm{J}_{\mathrm{QV}}-\mathrm{J}_{\mathrm{Q} \theta} \mathrm{J}_{\mathrm{P} \theta^{-1}} \mathrm{~J}_{\mathrm{PV}}\right] \Delta \mathrm{V}=\mathrm{J}_{\mathrm{R}} \Delta \mathrm{V} \\
\Delta \mathrm{V}=\mathrm{J}^{-1}-\Delta \mathrm{Q}
\end{gathered}
$$

Where

$$
\mathrm{J}_{\mathrm{R}}=\left(\mathrm{J}_{\mathrm{QV}}-\mathrm{J}_{\mathrm{Q} \theta} \mathrm{J}_{\mathrm{P} \theta^{-1}} \mathrm{JPV}\right)
$$

$\mathrm{J}_{\mathrm{R}}$ is called the reduced Jacobian matrix of the system.

\subsection{Modes of Voltage instability}

Voltage Stability characteristics of the system can be identified by computing the Eigen values and Eigen vectors Let

$$
\mathrm{J}_{\mathrm{R}}=\xi \eta
$$

Where,

$\xi=$ right eigenvector matrix of $J_{R}$

$\eta=$ left eigenvector matrix of $J_{R}$

$\bigwedge=$ diagonal eigenvalue matrix of $J_{R}$ and

$$
\mathrm{J}_{\mathrm{R}^{-1}}=\xi^{-1} \eta
$$

From (3) and (6), we have

$$
\Delta \mathrm{V}=\xi^{-1} \eta \Delta \mathrm{Q}
$$

or

$$
\Delta \mathrm{V}=\sum_{\mathrm{I}} \frac{\xi_{\mathrm{i}} \eta_{\mathrm{i}}}{\lambda_{\mathrm{i}}} \Delta \mathrm{Q}
$$

Where $\xi_{\mathrm{i}}$ is the $\mathrm{i}_{\text {th }}$ column right eigenvector and $\eta$ the $\mathrm{i}_{\text {th }}$ row left eigenvector of $J_{R}$.

$\lambda_{i}$ is the ith Eigen value of $J_{R}$.

The $i_{\text {th }}$ modal reactive power variation is,

$$
\Delta \mathrm{Q}_{\mathrm{mi}}=\mathrm{K}_{\mathrm{i}} \xi_{\mathrm{i}}
$$

where,

$$
\mathrm{K}_{\mathrm{i}}=\sum_{\mathrm{j}} \xi_{\mathrm{ij}}{ }^{2}-1
$$

Where

$\xi_{\mathrm{ji}}$ is the $\mathrm{j}_{\text {th }}$ element of $\xi_{\mathrm{i}}$

The corresponding $i_{\text {th }}$ modal voltage variation is

$$
\Delta \mathrm{V}_{\mathrm{mi}}=\left[1 / \lambda_{\mathrm{i}}\right] \Delta \mathrm{Q}_{\mathrm{mi}}
$$

It is seen that, when the reactive power variation is along the direction of $\xi_{\mathrm{i}}$ the corresponding voltage variation is 
also along the same direction and magnitude is amplified by a factor which is equal to the magnitude of the inverse of the $i_{\text {th }}$ eigenvalue. In this sense, the magnitude of each eigenvalue $\lambda_{\mathrm{i}}$ determines the weakness of the corresponding modal voltage. The smaller the magnitude of $\lambda_{i}$, the weaker will be the corresponding modal voltage. If $\left|\lambda_{i}\right|=0$ the $i_{\text {th }}$ modal voltage will collapse because any change in that modal reactive power will cause infinite modal voltage variation.

In (8), let $\Delta \mathrm{Q}=\mathrm{e}_{\mathrm{k}}$ where $\mathrm{e}_{\mathrm{k}}$ has all its elements zero except the kth one being 1 . Then,

$$
\Delta V=\sum_{\mathrm{i}} \frac{\eta_{1 \mathrm{k}} \xi_{1}}{\lambda_{1}}
$$

$\eta_{1 \mathrm{k}} \quad \mathrm{k}$ th element of $\eta_{1}$

$\mathrm{V}-\mathrm{Q}$ sensitivity at bus $\mathrm{k}$

$$
\frac{\partial \mathrm{V}_{\mathrm{K}}}{\partial \mathrm{Q}_{\mathrm{K}}}=\sum_{\mathrm{i}} \frac{\eta_{1 \mathrm{k}} \xi_{1}}{\lambda_{1}}=\sum_{\mathrm{i}} \frac{\mathrm{P}_{\mathrm{ki}}}{\lambda_{1}}
$$

\section{Problem Formulation}

The objectives of the reactive power dispatch problem considered here is to minimize the system real power loss and maximize the static voltage stability margins (SVSM). This objective is achieved by proper adjustment of reactive power variables like generator voltage magnitude ( $g i$ ) $\mathrm{V}$, reactive power generation of capacitor bank (Qci), and transformer tap setting $\left(\mathrm{t}_{\mathrm{k}}\right)$. Power flow equations are the equality constraints of the problems, while the inequality constraints include the limits on real and reactive power generation, bus voltage magnitudes, transformer tap

$$
\begin{gathered}
P_{G i}-P_{D i}-V_{i \sum_{j=1}^{n b} V_{j}}\left[\begin{array}{c}
G_{i j} \\
+B_{i j}
\end{array}\right. \\
Q_{G i}-Q_{D i}-V_{i \sum_{j=1}^{n b} V_{j}}\left[\begin{array}{c}
G_{i j} \\
+B_{i j}
\end{array}\right.
\end{gathered}
$$

where, $n b$ is the number of buses, $P_{G}$ and $Q_{G}$ are the real and reactive power of the generator, $P_{D}$ and $Q_{D}$ are the real and reactive load of the generator, and $G_{i j}$ and $B_{i j}$ are the mutual conductance and susceptance between bus $i$ and bus $j$.Generator bus voltage $\left(V_{G i}\right)$ inequality constraint:

$$
V_{G i}^{\min } \leq V_{G i} \leq V_{G i}^{\max }, i \in n g
$$

Load bus voltage $\left(V_{L i}\right)$ inequality constraint:

$$
V_{L i}^{\min } \leq V_{L i} \leq V_{L i}^{\max }, i \in n l
$$

Switchable reactive power compensations $\left(Q_{C i}\right)$ inequality constraint:

$$
Q_{C i}^{\min } \leq Q_{C i} \leq Q_{C i}^{\max }, i \in n c
$$

Reactive power generation $\left(Q_{G i}\right)$ inequality constraint:

$$
Q_{G i}^{\min } \leq Q_{G i} \leq Q_{G i}^{\max }, i \in n g
$$

Transformers tap setting $\left(T_{i}\right)$ inequality constraint: positions and line flows

\subsection{Minimization of Real Power Loss}

It is aimed in this objective that minimizing of the real power loss (Ploss) in transmission lines of a power system. This is mathematically stated as follows.

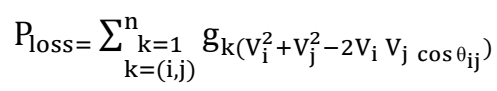

Where $\mathrm{n}$ is the number of transmission lines, $\mathrm{g}_{\mathrm{k}}$ is the conductance of branch $\mathrm{k}, \mathrm{V}_{\mathrm{i}}$ and $\mathrm{V}_{\mathrm{j}}$ are voltage magnitude at bus $\mathrm{i}$ and bus $\mathrm{j}$, and $\theta \mathrm{ij}$ is the voltage angle difference between bus $\mathrm{i}$ and bus $\mathrm{j}$.

\subsection{Minimization of Voltage Deviation}

It is aimed in this objective that minimizing of the Deviations in voltage magnitudes (VD) at load buses. This is mathematically stated as follows.

$$
\text { Minimize VD }=\sum_{\mathrm{k}=1}^{\mathrm{nl}}\left|\mathrm{V}_{\mathrm{k}}-1.0\right|
$$

Where $\mathrm{nl}$ is the number of load busses and $\mathrm{V}_{\mathrm{k}}$ is the voltage magnitude at bus $\mathrm{k}$.

\subsection{System Constraints}

In the minimization process of objective functions, some problem constraints which one is equality and others are inequality had to be met. Objective functions are subjected to these constraints shown below.

Load flow equality constraints:

$$
\begin{aligned}
& \left.\begin{array}{c}
\cos \theta_{i j} \\
\sin \theta_{i j}
\end{array}\right]=0, i=1,2 \ldots, n b \\
& \left.\begin{array}{c}
\cos \theta_{i j} \\
\sin \theta_{i j}
\end{array}\right]=0, i=1,2 \ldots, n b
\end{aligned}
$$

$$
T_{i}^{\min } \leq T_{i} \leq T_{i}^{\max }, i \in n t
$$

Transmission line flow $\left(\mathrm{S}_{\mathrm{Li}}\right)$ inequality constraint:

$$
S_{L i}^{\min } \leq S_{L i}^{\max }, i \in n l
$$

Where, nc, ng and nt are numbers of the switchable reactive power sources, generators and transformers.

\section{Bacterial Foraging Optimization Algorithm}

Bacterial Foraging optimization is based on foraging behavior of Escherichia coli (E.coli) bacteria present in the human intestine and been already implemented to real world problems [13]. In this foraging theory, the objective of the animal is to search for and obtain nutrients in a fashion that energy intake per unit time $(\mathrm{E} / \mathrm{T})$ is minimized [11]. A group of bacteria move in search of food and away 
from noxious elements known as Foraging. BFO algorithm draws its inspiration from this foraging behaviour. Bacteria have a tendency to gather to the nutrient-rich areas by activity called Chemo taxis. Its movement and behaviour is characterized by the spinning flagella which acts as a Biological motor and helps bacteria to swim. An e.coli bacterium has 8-10 flagella placed randomly on its body with a speed of 100-200 rps. An E.coli bacteria alternates through running and tumbling. Running speed is $10-20 \mathrm{~m}=\mathrm{s}$ and they cannot swim straight. The flagella can rotate either clockwise or counter clockwise. When all the flagella rotate counter clockwise, they form a compact, helically propelling the cell along a trajectory, which is called "run". When the flagella rotate in clockwise direction they enable the bacterium to move in different directions and cause bacteria to "tumble". The bacterial foraging process consists mainly of four sequential mechanisms namely chemo taxis, swarming and reproduction and eliminationdispersal.

a. Chemo taxis:- An E.coli bacterium can move in two different ways: it can run (swim for a period of time) or tumble and alternates between these movements throughout its travel in search of food. In BFO, a unit walk with random direction represents a "tumble" and a unit walk with the same direction in the last step indicates "run". In the computational chemo taxis, the movement of $i^{\text {th }}$ bacterium after one step can be represented as

$$
\theta^{i}(j+1, k, l)=\theta^{i}(j, k, l)+C(i) \varphi(j)
$$

Here $\theta^{i}(j, k, l)$ denotes the location of $\mathrm{i}^{\text {th }}$ bacterium at $\mathrm{j}^{\text {th }}$ chemo tactic $\mathrm{k}^{\text {th }}$ reproductive and $\mathrm{l}^{\text {th }}$ elimination and dispersal step. C(i) is the length of unit walk, which is constant in basic BFO and $\varphi(j)$ is the direction angle of the $\mathrm{j}^{\text {th }}$ step. When the bacterium is in run mode $\varphi(j)$ is same as $\varphi(j-1)$, otherwise $\varphi(j)$ is a random angle directed within a range of $[0,2 \Pi]$. If the cost at $\theta^{i}(j+1, k, l)$ is better than the cost at $\theta^{i}(j, k, l)$, then the bacterium takes another step of size $\mathrm{C}(\mathrm{i})$ in that direction otherwise it is allowed to tumble. This process is repeated until the number of steps taken is greater than the number of iterations in chemo tactic loop, $\mathrm{N}_{\mathrm{c}}$

b. Swarming: - A bacterium in times of stresses releases attractants to signal the bacteria to swarm together. Each bacterium also releases repellent to signal the others to be at a minimum distance from it. Thus all of them will have a cell to cell attraction via attractant and cell to cell repulsion via repellent. The cell to cell signaling in E.coli swarm may be mathematically represented as

$$
\begin{gathered}
j_{c c}(\theta, P(j, k, l))=\sum_{i=1}^{s} j_{c c}\left(\theta, \theta^{i}(j, k, l)\right)= \\
\sum_{i=1}^{s}\left[-d_{\text {attractant }} \exp \left(-\delta_{\text {attractant }} \sum_{m=1}^{p}\left(\theta_{m}-\theta_{m}^{i}\right)^{2}\right)\right]+\sum_{i=1}^{s}\left[h_{\text {repellent }} \exp \left(-\delta_{\text {repellent }} \sum_{m=1}^{p}\left(\theta_{m}-\theta_{m}^{i}\right)^{2}\right)\right]
\end{gathered}
$$

Here $j_{c c}(\theta, P(j, k, l))$ represents objective function value to be added to actual objective function, $S$ is the total number of bacteria, $\mathrm{P}$ is the number of parameters to be optimized and $\theta=\left[\theta_{1}, \theta_{2}, \ldots, \theta_{P}\right]^{T}$ is a point in pdimensional search domain. $\mathrm{d}_{\text {attractant }}$ is the depth of attractant released by the cell and $\delta_{\text {attractant }}$ is the measure of width of the attractant signal. $\mathrm{h}_{\text {repellent }}=\mathrm{d}_{\text {attractant }}$ is the height of repellant effect magnitude, $\delta_{\text {repellent }}$ is a measure of width of repellant. These coefficients are to be taken judiciously.

c. Reproduction:- After the completion of all $\mathrm{N}_{\mathrm{c}}$ chemo tactic steps a reproduction step takes place. Fitness value of the bacteria is stored in ascending order. The lower half of bacteria having a higher fitness die and remaining $S_{r}=S / 2$ bacteria are allowed to split into two identical one. Thus the population after reproduction remains constant.

d. Elimination and Dispersal: - There is a probability that bacteria may be stuck around the initial or local optima positions, it is required to diversify the bacteria either gradually or suddenly so that the possibility of being trapped in to local minima is eliminated and global optima is obtained. The dispersion operation takes place after a certain number of reproduction processes. A bacterium is chosen, according to a present probability $p_{\text {ed }}$, to be dispersed and moved to another position within the environment. This may disturb optimization process but prevent the local minima trapping.

\section{Bacterial Foraging Oriented with Particle Swarm Optimization (BF-PSO)}

BF-PSO algorithm combines both BFO and PSO. The aim is to make PSO ability to exchange social information and BF ability in finding new solution by elimination and dispersal, a unit length direction of tumble behavior is randomly generated. Random direction may lead to delay in reaching the global solution. In "BF-PSO" algorithm the unit length random direction of tumble behavior can be decided by the global best position and the best position of each bacterium. During the chemo taxis loop tumble direction is updated by:

$$
\varphi(j+1)=\omega * \varphi(j)+C_{1} * \text { rand } *(\text { pbest }- \text { pcurrent })+c_{2} * \text { rand } *(\text { gbest }- \text { pcurrent })
$$

Where pbest is the best position of each bacterium and gbest is the global best bacterium. The brief pseudo-code of BF-PSO has been provided below. Algorithm to solve optimal dispatch problem described below

[Step 1] Initialize the $\mathrm{p}, \mathrm{S}, \mathrm{N}_{\mathrm{c}}, \mathrm{N}_{\mathrm{s}}, \mathrm{N}_{\mathrm{re}}, \mathrm{N}_{\mathrm{ed}}, \mathrm{p}_{\mathrm{ed}}, \mathrm{C}(\mathrm{i})(\mathrm{i}=1,2,3, . ., \mathrm{S}) \theta^{i}$ parameters 
where

$\mathrm{p}$-Dimension of the search space;

$\mathrm{S}$-Number of bacteria in the population;

$\mathrm{N}_{\mathrm{s}}$-Swimming length after which tumbling of bacteria will be undertaken in chemotactic loop;

$\mathrm{N}_{\mathrm{c}}$-The number of iterations to be undertaken in chemotactic loop, always $\mathrm{Nc}>\mathrm{Ns}$;

$\mathrm{N}_{\mathrm{re}}$-Maximum no. of reproduction steps;

$\mathrm{N}_{\mathrm{ed}}$-the maximum no. of Elimination and dispersal events to be imposed over bacteria;

$p_{e d}$-Probability with which elimination and dispersal will continue;

$\theta^{i}$-Location of the $\mathrm{i}^{\text {th }}(\mathrm{i}=1,2,3, . ., \mathrm{S})$ bacterium;

C(i) -Step size of the $i^{\text {th }}$ bacterium taken in random direction, specified by tumble. Generate a random vector $\varphi(j)$ in the range [-11] $\mathrm{C}_{1}, \mathrm{C}_{2}, \omega$ : PSO parameters

[Step 2] Elimination and dispersal loop: $1=1+1$

[Step 3] Reproduction loop: $\mathrm{k}=\mathrm{k}+1$

[Step 4] Chemo taxis loop: $\mathrm{j}=\mathrm{j}+1$

[Step 5] If $\mathrm{j}<\mathrm{Nc}$, go to [Step 4]. In this case, continue chemo taxis since the life of the bacteria is not over.

[Step 6] Reproduction

[Step 7] If $k<\mathrm{N}_{\mathrm{re}}$, go to the [Step 3]. Since in this case the specified reproduction steps are not reached, start the next generation of the chemo tactic loop.

[Step 8] Elimination-dispersal: For $\mathrm{i}=1,2, . ., \mathrm{S}$ with the probability $\mathrm{p}_{\mathrm{ed}}$, eliminate and disperse each bacterium, which results in keeping number of bacteria in the population constant. To do this, if a bacterium is eliminated, simply disperse one to a random location on the optimization domain. If $1<\mathrm{N}_{\mathrm{ed}}$ then go to [Step 2], otherwise end;

\section{Adaptive Bacterial Foraging Oriented Particle Swarm Optimization (ABF-PSO)}

To enhance the performance of BF-PSO we had proposed Adaptive Bacterial Foraging Oriented Particle Swarm Optimization (ABF-PSO). Chemo taxis is a foraging strategy that implements a type of local optimization where the bacteria try to climb up the nutrient concentration, avoid noxious substance and search for ways out of neutral media. A chemo tactic step size varying as the function of the current fitness value is expected to provide better convergence behavior as compared to a fixed step size. A simple adaption scheme for the step size for $i_{\text {th }}$ bacterium given in following equation

$$
C(i)=\frac{\left|j^{i}(\theta)\right|}{\left|j^{i}(\theta)+\Psi\right|}=\frac{1}{1+\frac{\Psi}{j^{i}(\theta)}}
$$

Where $\Psi$ is positive constant.

$j^{i} \theta=$ cost function of the ith bacterium.

$C(i)=$ variable run (step) length of $i_{\text {th }}$ bacterium.
If $j^{i} \theta$ tends to zero then $C(i) \rightarrow 0$ and when $j^{i} \theta \rightarrow$ large, $C(i) \rightarrow 0$. This implies that the bacterium which is in the vicinity of noxious substance associates with higher cost function. Hence it takes larger steps to migrate to a place with higher nutrient concentration. Use of Eqn (27) in Eqn (24) is expected to give improved convergence performance compared to fixed step size due to the above phenomenon.

[Step 1] Same as that of BF-PSO based optimization

[Step 2-3] Same as that of BF-PSO, but only difference is that while updating location in Eqn (24) (and also in swim) the adaptive run length unit, C(i) defined in Eqn (27) is used instead of fixed run length unit.

[Step 5-8] Same as that of BF-PSO based technique.

\section{Simulation Results}

The validity of the proposed Algorithm technique is demonstrated on IEEE-30 bus system. The IEEE-30 bus system has 6 generator buses, 24 load buses and 41 transmission lines of which four branches are (6-9), (6-10), (4-12) and (28-27) - are with the tap setting transformers. The real power settings are taken from [1]. The lower voltage magnitude limits at all buses are 0.95 p.u. and the upper limits are 1.1 for all the PV buses and 1.05 p.u. for all the PQ buses and the reference bus.

Table 1. Voltage Stability under Contingency State

\begin{tabular}{cccc}
\hline Sl.No & Contigency & ORPD Setting & Vscrpd Setting \\
\hline 1 & $28-27$ & 0.1400 & 0.1422 \\
2 & $4-12$ & 0.1658 & 0.1662 \\
3 & $1-3$ & 0.1784 & 0.1754 \\
4 & $2-4$ & 0.2012 & 0.2032 \\
\hline
\end{tabular}

Table 2. Limit Violation Checking Of State Variables

\begin{tabular}{|c|c|c|c|c|}
\hline \multirow{2}{*}{ State variables } & \multicolumn{2}{|c|}{ limits } & \multirow{2}{*}{ ORPD } & \multirow{2}{*}{ VSCRPD } \\
\hline & Lower & upper & & \\
\hline Q1 & -20 & 152 & 1.3422 & -1.3269 \\
\hline Q2 & -20 & 61 & 8.9900 & 9.8232 \\
\hline Q5 & -15 & 49.92 & 25.920 & 26.001 \\
\hline Q8 & -10 & 63.52 & 38.8200 & 40.802 \\
\hline Q11 & -15 & 42 & 2.9300 & 5.002 \\
\hline Q13 & -15 & 48 & 8.1025 & 6.033 \\
\hline V3 & 0.95 & 1.05 & 1.0372 & 1.0392 \\
\hline V4 & 0.95 & 1.05 & 1.0307 & 1.0328 \\
\hline V6 & 0.95 & 1.05 & 1.0282 & 1.0298 \\
\hline V7 & 0.95 & 1.05 & 1.0101 & 1.0152 \\
\hline V9 & 0.95 & 1.05 & 1.0462 & 1.0412 \\
\hline V10 & 0.95 & 1.05 & 1.0482 & 1.0498 \\
\hline V12 & 0.95 & 1.05 & 1.0400 & 1.0466 \\
\hline V14 & 0.95 & 1.05 & 1.0474 & 1.0443 \\
\hline V15 & 0.95 & 1.05 & 1.0457 & 1.0413 \\
\hline V16 & 0.95 & 1.05 & 1.0426 & 1.0405 \\
\hline V17 & 0.95 & 1.05 & 1.0382 & 1.0396 \\
\hline V18 & 0.95 & 1.05 & 1.0392 & 1.0400 \\
\hline V19 & 0.95 & 1.05 & 1.0381 & 1.0394 \\
\hline V20 & 0.95 & 1.05 & 1.0112 & 1.0194 \\
\hline V21 & 0.95 & 1.05 & 1.0435 & 1.0243 \\
\hline V22 & 0.95 & 1.05 & 1.0448 & 1.0396 \\
\hline V23 & 0.95 & 1.05 & 1.0472 & 1.0372 \\
\hline V24 & 0.95 & 1.05 & 1.0484 & 1.0372 \\
\hline
\end{tabular}




\begin{tabular}{ccccc}
\hline \multirow{2}{*}{ State variables } & \multicolumn{2}{c}{ limits } & \multirow{2}{*}{ ORPD } & \multirow{2}{*}{ VSCRPD } \\
\hline V25 & 0.95 & 1.05 & 1.0142 & 1.0192 \\
V26 & 0.95 & 1.05 & 1.0494 & 1.0422 \\
V27 & 0.95 & 1.05 & 1.0472 & 1.0452 \\
V28 & 0.95 & 1.05 & 1.0243 & 1.0283 \\
V29 & 0.95 & 1.05 & 1.0439 & 1.0419 \\
V30 & 0.95 & 1.05 & 1.0418 & 1.0397 \\
\hline
\end{tabular}

Table 3. Comparison of Real Power Loss

\begin{tabular}{lc}
\hline Method & Minimum loss \\
\hline Evolutionary programming[14] & 5.0159 \\
Genetic algorithm[15] & 4.665 \\
Real coded GA with Lindex as SVSM[16] & 4.568 \\
Real coded genetic algorithm[17] & 4.5015 \\
Proposed ABF-PSO method & 4.1368 \\
\hline
\end{tabular}

\section{Conclusion}

In this paper a novel approach ABF-PSO algorithm used to solve optimal reactive power dispatch problem, considering various generator constraints, has been successfully applied.The performance of the proposed algorithm demonstrated through its voltage stability assessment by modal analysis is effective at various instants following system contingencies. Also this method has a good performance for voltage stability Enhancement of large, complex power system networks. The effectiveness of the proposed method is demonstrated on IEEE 30-bus system.

\section{References}

[1] O.Alsac, and B. Scott, "Optimal load flow with steady state security”,IEEE Transaction. PAS -1973, pp. 745-751.

[2] Lee K Y ,Paru Y M , Oritz J L -A united approach to optimal real and reactive power dispatch , IEEE Transactions on power Apparatus and systems 1985: PAS$104: 1147-1153$

[3] A.Monticelli , M .V.F Pereira ,and S. Granville , "Security constrained optimal power flow with post contingency corrective rescheduling" , IEEE Transactions on Power Systems :PWRS-2, No. 1, pp.175-182.,1987.

[4] Deeb N ,Shahidehpur S.M ,Linear reactive power optimization in a large power network using the decomposition approach. IEEE Transactions on power system 1990: 5(2) : 428-435
[5] E. Hobson ,'Network consrained reactive power control using linear programming, ' IEEE Transactions on power systems PAS -99 (4) ,pp 868-877, 1980

[6] K.Y Lee ,Y.M Park, and J.L Oritz, "Fuel -cost optimization for both real and reactive power dispatches" , IEE Proc; 131C,(3), pp.85-93.

[7] M.K. Mangoli, and K.Y. Lee, "Optimal real and reactive power control using linear programming", Electr.Power Syst.Res, Vol.26, pp.1-10,1993.

[8] S.R.Paranjothi ,and K.Anburaja, "Optimal power flow using refined genetic algorithm”, Electr.Power Compon.Syst, Vol. $30,1055-1063,2002$.

[9] D. Devaraj, and B. Yeganarayana, "Genetic algorithm based optimal power flow for security enhancement”, IEE procGeneration.Transmission and. Distribution; 152, 6 November 2005.

[10] C.A. Canizares , A.C.Z.de Souza and V.H. Quintana , " Comparison of performance indices for detection of proximity to voltage collapse," vol. 11. no.3 , pp.1441-1450, Aug 1996.

[11] Passino, K.M., 2002. Bio mimicry of bacterial foraging for distributed optimization and control. IEEE Control Systems Magazine, pp. 52-67.

[12] Karoni,W., 2008. Bacterial foraging oriented by particle swarm optimization strategy for PID tuning. In GECCO 2008: Proceedings of the Genetic and Evolutionary computation conf, pp. 1823-1826, ACM.

[13] Dasgupta, S., Das, S., Abraham, A., Biswas, A., 2009. Adaptive Computational Chemotaxis in Bacterial Forgaing Optimization: An Analysis. IEEE Trans on Evolutionary Comp., vol. 13, pp. 919-941.

[14] Wu Q H, Ma J T. Power system optimal reactive power dispatch using evolutionary programming. IEEE Transactions on power systems 1995; 10(3): 1243-1248 .

[15] S.Durairaj, D.Devaraj, P.S.Kannan ,' Genetic algorithm applications to optimal reactive power dispatch with voltage stability enhancement', IE(I) Journal-EL Vol 87,September 2006.

[16] D.Devaraj,' Improved genetic algorithm for multi objective reactive power dispatch problem' European Transactions on electrical power 2007 ; 17: 569-581.

[17] P. Aruna Jeyanthy and Dr. D. Devaraj "Optimal Reactive Power Dispatch for Voltage Stability Enhancement Using Real Coded Genetic Algorithm" International Journal of Computer and Electrical Engineering, Vol. 2, No. 4, August, $20101793-8163$. 